\title{
Използвана литература
}

1. Велковска, Г., 2014г., Устройство на територията - законодателни и практически аспекти, , издателство „Нико-96“ - гр.Казанльк, стр.40-44, ISBN: 978-619-7145-04-5;

2. Велковски, В., 2021г., Устройствени мероприятия върху земеделски земи - аспекти, проблеми, механизми, CD, издателство „Валдес-ВB-ГВ““- София, стр.41-44, ISBN: 978-954-9875-94-2;

3. Закон за опазване на селскостопанското имущество, в сила от 01.10.1974 г.

отразена деноминацията от 05.07.1999г.,обн. ДВ. бр.54 от 12 юли 1974г., изм. ДВ. бр.58 от 18 юли 2017г;

4. Наредба № 49, издадена от Министерството на земеделието, храните и горите, обн. ДВ. бр.102 от 19 ноември 2004г., попр. ДВ. бр.113 от 28 декември 2004г., изм. и доп. ДВ. бр.92 от 6 Ноември 2018г.;

5. Закон за наследството, в сила от 30.04.1949г., обн. ДВ. бр.22 от 29 януари 1949г., попр. ДВ. бр.41 от 21 февруари 1949г., изм. ДВ. бр.47 от 23 юни 2009г.;

6. Закон за възстановяване на собствеността върху горите и земите от горски фонд, отразена деноминацията от 05.07.1999 г., обн. ДВ. бр.110 от 25 ноември 1997г., изм. ДВ. бр.58 от 18 Юли 2017г., доп. ДВ. бр.55 от 3 Юли 2018г.;

7. www. ciela.net;

8. Internet.

\section{Информация за контакт с автора:}

Д-р Валери Велковски

Министерство на земеделието, храните и горите

София, България

e-mail: jurist57@abv.bg 


\title{
ПОКУПКАТА НА ЗЕМЕДЕЛСКА ЗЕМЯ С ФИНАНСОВ ИНСТРУМЕНТ - КЛЮЧОВ КОМПОНЕНТ ЗА УСТОЙЧИВОСТТА НА ФЕРМАТА
}

\author{
Редовен докторант Милен Влаев \\ Икономически университет - Варна

\section{PURCHASE ARABLE LAND WITH FINANCING INSTRUMENT - THE KEY COMPONENT FOR SUSTAINABLE DEVELOPMENT OF FARM}

\author{
PhD Student Milen Vlaev \\ University of Economics - Varna
}

DOI: https://doi.org/10.36997/SLM2019.83

\begin{abstract}
Резюме
Българският пазар на земя се променя бързо през последното десетилетие и дава на земеделските производители различни възможности за увеличаване на бизнес резултатите им. Целта на доклада е да се проучат и представят възможностите за достъп до кредитни ресурси за закупуване на земеделска земя в България. В проучването се използват общи и специфични методи за оченка и анализ. Резултатите са насочени към идентифициране на бизнес перспективите за използване на банков кредитен или лизингов продукт за развитие на бизнеса, с иел закупуване на земя. Обект на изследването е, коя алтернатива - покупката на земя или наем, дава по - добра възможност за устойчиво развитие на земеделските производители. Изводите са насочени към демонстриране на значимостта на придобиването на основни активи като земя за производство и възможностите, които се предлагат за това в България.
\end{abstract}

Ключови думи: земеделска земя; инвестииионен кредит; финансиране; аренден договор; възвращаемост на капитала; устойчивост; балансова структура; лихвен процент

JEL Класификация: Q12; Q15

Abstract

The Bulgarian land market has been changed rapidly over the last decade and gives various opportunities to increase the farmers business results. The aim of the report is to research and present opportunities for access to loan for the purchase of agricultural land in Bulgaria. The research uses general and specific assessment and analysis methods. The results are focusing to identifying the business prospects for utilization a bank loan or leasing's product for business development, through the purchase or lease the land. Determination the best opportunities from them for sustainable development for farmers. The target of conclusion is to be confirm the importance of acquiring basic assets as land for production and the opportunities that is offer for this in Bulgaria.

Keywords: agricultural land; investment credit; financing; lease contract; return on capital; sustainability; balance sheet structure; interest rate

JEL Classification: Q12; Q15 
Земеделската земя е основен ресурс и средство за производство в селското стопанство. Тя е природна даденост, като се характеризира с многогодишни почвообразуващи процеси, които я правят невъзобновяем природен ресурс/актив. Земята притежава обективни измерители като, големина на парцел, местоположение, размер, граници, сервитути, така също притежава и качествено измерение, което се измерва с плодородие (присъщо на почвата), и включва почвено климатични особености, достъп до комуникация, водни, човешки и природни ресурси. Прието е земята да се класира по категории от пьрва до десета, като това не е определящ фактор за цената й. В повечето случаи инвестициите в земеделска земя не следва да се водят само до категорията и цената на земеделската земя, а да се разгледа в съвкупност, отговаря ли тя на нуждите на инвеститора и целите му, наличен ли е достатъчно голям и ликвиден вторичен пазар. За това е важно да уточним, че земята не носи спекулативна стойност за фермерите. Като основен актив за производство, включвайки я в основния стопански живот, тя придобива активна стойност за стопанството, което се измерва от доставчиците, кредиторите и другите контрагенти и партньори на фермера. В този смисъл в статията се обръща внимание на важността на земеделската земя за фермера и факторите, които могат да повлияят върху цената й, а оттам и на рентабилността на стопанството и икономическото значение на оценката от контрагентите му.

Едно от важните качества на земеделската земя е, че тя не се износва (амортизира) при нормалното й използване като при другите средства за производство. В процеса на правилни обработки тя успява дори да повиши своето естествено плодородие. Влагайки капитал под формата на торове, специфични почвени операции, облагородяване и изграждане на мелиоративни съоръжения, включвайки я в комасация с други съседни парцели се въздейства освен върху плодородието, но пряко може да се влияе и върху стойността й. На този фон можем да приемем, че земеделската земя се явява капитал, в който може неограничено да се инвестира, увеличавайки цената му във времето. Инвестираният капитал следва да има икономически смисъл и да е в унисон с бизнес стратегията на фирмата, влияейки пряко върху основните икономически показатели като рентабилност, печалба и възвръщаемост на собствения капитал. В този смисъл управленските решения могат да окажат пряко влияние върху цената на земеделската земя, но за да разгледаме ефекта от подобна инвестиция то тя трябва да бъде разгледана в цялост. Следва да обърнем внимание и какви са външните фактори извън влиянието на мениджмънта на фермера, които пряко оказват влияние върху цената на земеделската земя. 
На макроикономическо ниво в световен мащаб под влиянието на засиленото изграждане на инфраструктура, засилващите се урбанизациионни процеси, в съчетание с непрекъснатото нарастване на населението, земеделските земи са подложени на силно ограничаване поради характера си на изчерпаем ресурс. Според DW /Дойче веле/ всеки ден в Германия "изчезват" по близо 90 хектара земя, като от 1992 година насам общо 820 000 хектара са сменили статута си. Тази тенденция за намаляване на площите със земеделска земя се наблюдава в цял свят водена от горепосочените фактори. В Европа има достатъчно примери за ограничаване на този ресурс, чрез строежите на фотоволтаични инсталации и вятърни генератори върху плодородни земи, както и отчуждаването на частни имоти за инфраструктурни проекти, изискващи от двете страни на автомагистрали и железопътните трасета да се оставят "санитарни кордони", които се разполагат именно в земеделски площи. Според ООН през 2030 година в градска среда ще живеят общо около 5 милиарда души - с 1,35 милиарда повече, отколкото днес. Изчисленията са населението на земята да се увеличи до 9,8 милиарда до 2050 година. Замърсяването на земеделските площи, поради все по - голямата индустриализация и използването на земеделската земя за промишлени цели, оказва все по силно негативно влияние върху съществуващите земеделски площи. Като пример за това може да посочим, изграждането на открити рудници, ядрени аварии като Чернобил, Фукушима и много други.

В тази връзка плодородните земеделски земи в бъдеще ще придобиват все по ключов ресурс не само за земеделските производители, но също така ще имат и все поопределяща роля за оцеляването и изхранването на милиардите хора на планетата. Едно от решенията в тази посока, са увеличаване плодородието на обработваемите площи, чрез внедряване на нови технологии, подобряване на генетиката и инвестиции в напоителни системи. В повечето случаи в развиващите се страни, разположени на територията на континентите Африка и Южна Америка, това става за сметка на усвояване на площи от горския фонд, което пък има силно негативен ефект върху биоразнообразието и екологията в световен мащаб. Донякъде е възможно това може да допринесе за запазване на баланса в тьрсенето на обработваеми земеделски площи, но от друга страна, ще застраши крехкото екоравновесие на планетата. Изброените по-горе фактори, ясно очертават няколкото извода, че земята е ограничен ресурс подложен на натиск към намаление и като такъв ясно се очертава перспективата към поскъпване цената на земеделските площи, а оттам и на цените на самата земеделска продукция.

В унисон с казаното до тук, но на ниво държава, можем да маркираме кои са 
водещите фактори за увеличаване цената на земеделската земя и рентните плащания. Тук следва да се разгледат факторите, които влияят върху цената на земята, на ниво териториална единица или държава (Станимирова \& Христова, 2014). Факторите, определящи цената могат да се групират в няколко групи. Някой от по-важните фактори определящи цената на земеделската земя на национално ниво са:

1. Политиката на дотиране и субсидиране на земеделското производство: При субсидиране на селското стопанство до голяма степен се намалява инвестиционният риск, което води от своя страна до увеличаващо се търсене на земеделска земя, съответно до повишаване цената на земеделската земя и ренти. След приемането на България в ЕС, фермерите започват активно да усвояват потенциала на обработваемите площи предимно на база изоставена земеделски площи, като за периода от 2007 година до 2018 заявените площи за подпомагане и обработка нарастват с над 11 \% по данни на Министерство на земеделието и храните. На база изследвания (van Herck, Swinnen, \& Vranken, 2013) (Вълканов \& Гребеничарски, 2017) и от „ИнтелиАгро“ се доказва, че до голяма степен увеличението на цената на земята и рентата е в следствие от преките плащания на площ. Изчисленията показва, че на база увеличението на директните плащания с 1 евро, води до увеличение на рентите с между 13 и 25 евроцента. Друг важен и съществен елемент върху увеличаване цената на земеделската земя е и увеличената конкуренция сред „играчите“ търсещи земеделски площи, като в България навлязоха и много инвестиционни фондове, закупуващи земеделска земя, управлявайки над $3 \%$ от обработваемите площи, по данни на Асоциацията на собствениците на земеделска земя.

2. Реализирания доход от земеделието: Когато търсенето на земеделски стоки нараства, се повишават и цените на тези стоки. Това от своя страна води и до оскъпяване на факторите за производство, включително и на земеделската земя. До голяма степен ръста в цената на зърнените култури през 2012 и 2013 година, водят след себе си и поголям ръст в процентно отражение на цената на земята (Вж. фиг. 1).

3. Влияние на икономическите цикли в икономиката. Влошаването на икономическата среда и снижаване на възвръщаемостта на капитали, инвестирани в отделните отрасли води до пренасочване и търсене на други възможности за по- висока доходност на свободните парични средства. Тези тенденции ясно се виждат през 2009 и 2010 година, когато част от свободните капитали бяха насочени към земеделието, търсейки по-висока възвръщаемост на вложения капитал.

4. Прилаганата данъчната система спомага или намалява интереса към инвестиции в земеделската земя: Липсата на поземлен данък както и 
преференциалните данъчни облекчения от земеделска дейност при равни други условия, пораждат по-висока възвръщаемост на капитала, инвестиран в земеделието и повишават цената на земеделските земи. Към момента липсата на подобно данъчно облагане в България, благоприятства увеличаване на цените на земеделската земя и по- голямата доходност и ръст.

5. Цената на земеделска земя зависи най - вече и от облекченото и преференцилното кредитиране и финансиране на земеделското производство: Ниско лихвените кредити и лесния достьп до капитал повишават рентабилността в селското стопанство и гарантират възможността за лесно инвестиране в основни активи. По този начин земеделската земя може лесно да бъде придобита, а оттам да повиши и стойността си във времето.

1200

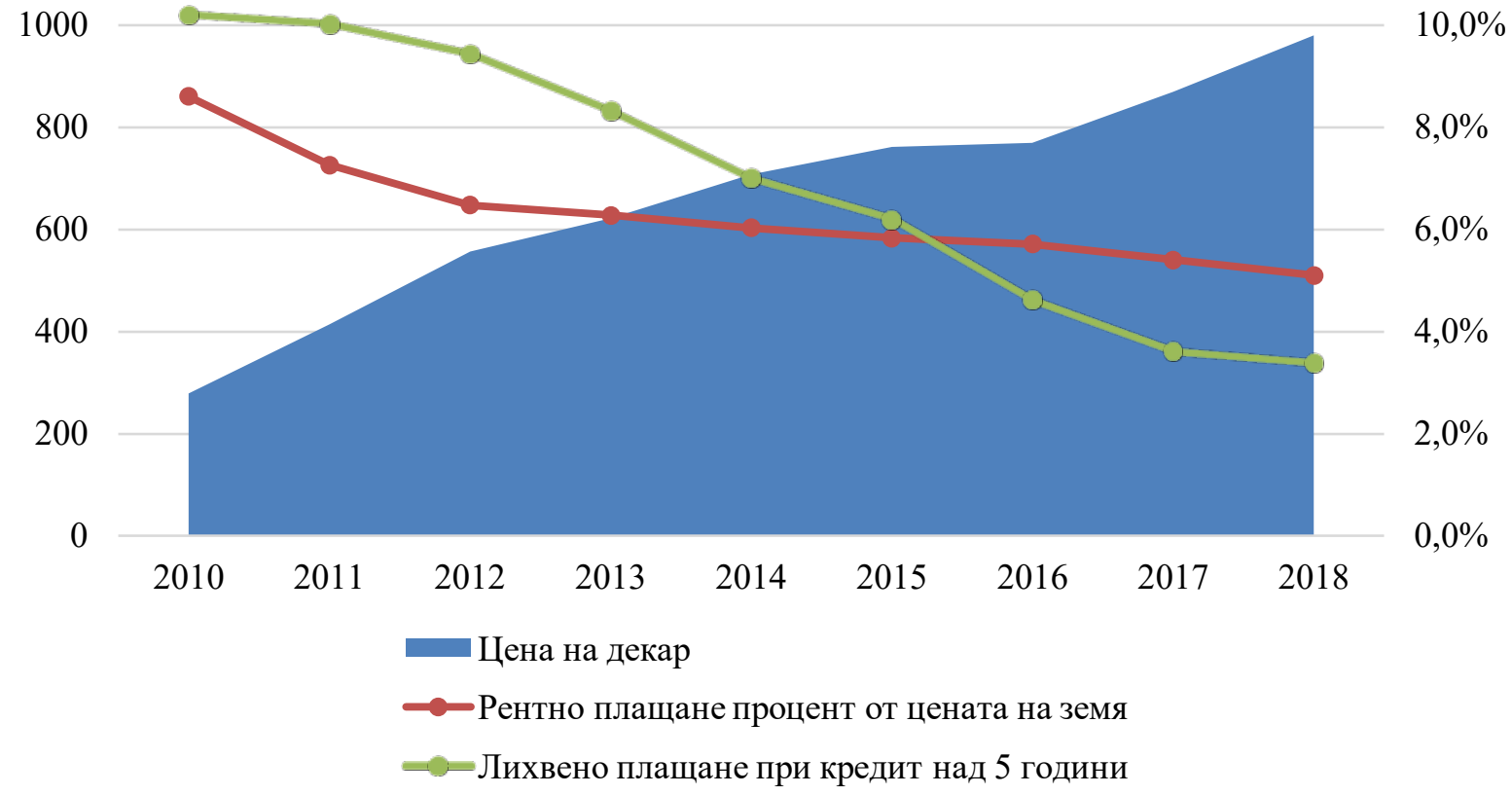

Фиг. 1. Процентно изменение на лихвените проценти спрямо ползвана рента

Разглеждайки възможностите за придобиване на земеделска земя в България ясно се очертава наличието на трайна тенденция за увеличаване стойността на земята във времето. Основните фактори са членството на страната в Европейския съюз и улеснения достъп до фондови и заемни капитали.

Един от разглежданите фактори ясно се откроява при определяне влиянието му върху ръста на цените на земята в България и това е лесния достъп до капитал (Kirechev, 
2019). Улеснения достъп може да се разгледа в контекста на предлаганите различни преференциални условия за този бизнес, като:

- Предлагането на различни специализирани инвестиционни кредитни продукти, като техния вид непрекъснато се увеличават през последните 10 години. Прилаганите различни форми на инвестиционни кредити, като инвестиционни кредитни линии, рамкови споразумения, различни лимити в комбинация с различни гратисни периоди, дават възможност за гъвкав подход при покупката на земеделска земя.

- Намалено изискване за самоучастие от страна на фермера в покупка на земеделска земя е водено от повишената ликвидност на земеделската земя като актив. Финансовите институции предлагат да финансират покупка на земеделска земя с минимално самоучастие в рамките от 10 до $15 \%$. При лизинговите и финансови компании сделката може да се сключи и без осигурено самоучастие когато клиентът предостави друг имот покриващ риска за банката като самоучастие. При стандартен инвестиционен кредит в повечето случаи се изисква минимум 20\% осигурено самоучастие от страна на бизнеса.

- Предлаганите дълги срокове на изплащане на кредитите за покупка на земеделска земя, сравнено със стандартните инвестиционни кредити позволява на бизнеса да изплаща кредит за срок до 15 години, като при стандартни инвестиционни кредити този срок обикновено е до 10 години.

- По-ниските цени на финансирането в сравнение с другите сектори, позволява на бизнеса да генерира по-добра рентабилност, съответно да има по-лесен достьп до капитал. За период от 2010 до 2018 година, ръста при кредитите в селското стопанство е 104\%, а за всички останали сектори е 4\%.

Лесния достъп до капитали, ще продължи да оказват силно влияние върху търсенето на земеделската земя а от там и до повишаване на цената и. Като пряко следствие от повишаване цената на земята, рентите ще бъдат подложени също на натиск да повишават стойността си. Доколкото това може да повлияе върху успеха на един земеделски стопанин, е необходимо да бъдат взети под внимание факторите, върху които не може да бъде повлияно, като размер на субсидии, данъчна тежест, цени на селскостопанската продукция. В тази връзка можем да измерим влиянието, съпоставяйки цените на инвестиционните фирмени кредити към заплащаните ренти за определен период.

Исторически можем да докажем, че към настоящия момент при финансиране на 
сделка за покупка на земеделска земя, лихвения разход, който земеделския стопанин ще заплати е в много по-малък размер на исканата аренда. Прогнозирайки, че цените на арендата и земеделската земя ще запазят своя възходящ тренд в средносрочен план, можем да разгледаме модельт със съпоставяне на лихвените и рентни плащания. Друг важен елемент е, че при покупка на земеделска земя, клиентьт ще има и повишен доход от увеличаване стойността на земята във времето и без да е инвестирал допълнително капитал в повишаване стойността на актива.

Възможността за придобиване на земеделска земя зависи преди всичко от възможността на компанията за генериране на достатъчна рентабилност, с цел отделянето на достатьчно капитал, с който да се изплаща покупката на земеделска земя. В България поради особеностите на пазара, цената на земеделската земя се покачи с над $250 \%$ за период от 8 години. За същия период лихвените проценти са подложени на обратна тенденция - спаднаха почти три пъти, а рентата се увеличи почти два пъти. Измерено съотношението на рентата към цената на земята, бележи спад с 50\%, за отчитания период. Видно от графиката по -долу може да заключим, че след 2015 година, ползването на банков кредит за закупуване на земеделска земя, в сравнение със заплащаната рента за 1 дка. наета/арендувана земя, е много по-изгодно! На фигурата е „изчистен“ елемента на доходността на актива, която той носи, в следствие на повишената цена на актива.

В унисон с фиг. 2 можем да измерим ефекта на инвестиция в рамките на 100000 лева, за закупена земеделска земя през 2010 година. Приемаме, че земеделската земя е закупена с кредит и към този момент фермер е можело да закупи 358 декара земеделска земя, по средна пазарна цена за България към 2010 година от 279 лева/1 дка. Финансовите институции предоставят финансиране в размер на 80 \% от исканата инвестиция и сравнението в таблицата по-долу е направено на база ползване на тази земеделска земя под наем и за изплащането й под формата на кредит. Направената инвестиция в земеделска земя, закупена с кредит, носи приблизително 60\% по-малко разходи за земеделските производители, отколкото заплащането на рента за наетата от тях земя. Имайки предвид, че ползването на кредит към началото на периода има определен времеви диапазон, в който намалението на лихвата може да намери отражение в размера на използвания кредит, без да отчитаме намалените плащания по лихвите в следствие на изплащане на главницата, можем да кажем, че моделът със закупуване на земеделска земя към момента е печеливш за Агробизнеса в България. 


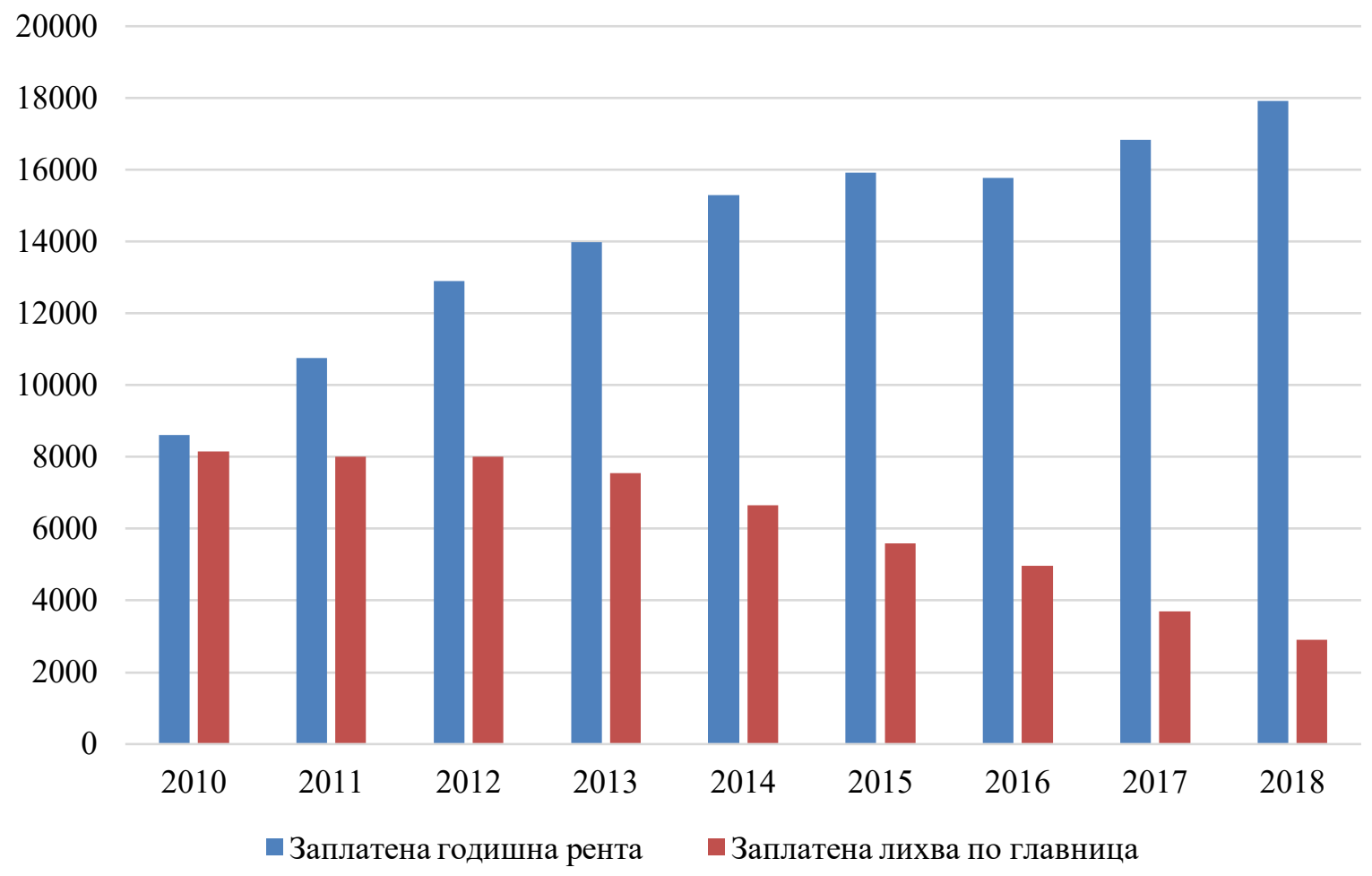

Фиг. 2 Инвестиция в земеделска земя с кредит спрямо наемането и под аренда исторически подход

На практика изплатената рента намалява печалбата на фермерите, като оказва влияе пряко върху нея. Лихвените разходи имат същия ефект, но за разлика от рентата, те имат определен матуритет /остатъчен срок до падежа на разрешен от банката кредит/, което прави лихвените плащания много по-стойностни при управлението на даден бизнес. Самата инвестиция в земеделска земя увеличава балансовото число и актива на клиента при изплащане на главницата по кредита, правейки текущите коефициенти на бизнеса много по-добри при разглеждане на документите от бъдещи инвеститори, кредитори и партньори. Самият актив не се амортизира, за разлика от другите активи и може да бъде повишавана неговата стойност във времето, изграждайки напоителни системи или пък окрупняването в по - големи парцели.

В заключение може да кажем, че голяма част от компаниите от Сектор селско стопанство имат собствена земеделска земя, което ги прави много по - устойчиви на пазара. На база собствени източници, разделяйки стопанствата по годишен оборот до 1 милион лева, от 1 до 3 милиона лева и над 3 милиона лева, можем да кажем, че в първата група фермерите със собствена земеделска земя са 46 \% от фирмите. Това основно се дължи на факта, че земеделските стопани закупуват земеделската земя като физически лица и компаниите от сектора имат структура на ЕТ и ЗП. При втората и трета група фирми с оборот над 1 милион лева 90\% от компаниите притежават собствена земеделска 
земя. Това до голяма степен се обуславя от просветляване на сектора в този сегмент и придобиването на активи предимно на фирмата. До голяма степен можем да кажем, че придобиването на активи на името на фирмата има и благоприятен ефект върху структурата на бизнеса.

В резултат на анализа, могат да се набележат следните по-важни изводи

- Компаниите в сектор селско стопанство следва да продължават да инвестират средства в покупката на земеделска земя, когато това е в унисон със стратегията на фирмата.

- Инвестициите в земеделска земя следва да се осъществява с инвестиционни кредити, които предоставят гъвкави условия и дълъг срок на изплащане.

- Покупката на земеделска земя води до по - благоприятното структуриране на бизнес показателите във фирмите и дава възможност за по- устойчиво развитие на бизнеса.

- Рентните плащания ще продължават да бъдат важен измерител на възвращаемостта на капитала в бизнеса.

- Цената на земеделската земя е подложена на влияние от фактори, които не зависят от мениджмънта на компаниите.

- Покупката на земеделска земя от земеделски производители в никакъв случай не може да се приравнява на инвестиционна сделка поради факта, че земеделската земя е основно средство за производство.

- Тенденциите пред цените на земеделската земя са да продължат да бъдат под натиск за повишаване.

\section{Използвана литература:}

1. Вълканов, Н., \& Гребеничарски, С. (2017). Пазарът на земеделска земя в България и ролята на директните плащания. София: Интелиагро.

2. Станимирова, М., \& Христова, С. (2014). Управление на поземлените ресурси. Варна: Наука и икономика.

3. Kirechev, D. (2019). Impact of bank lending on development of the agricultural sector in Bulgaria. 3th International Scientific Conference EMAN 2019: Economics \& Management: How to Cope With Disrupted Times (Selected Papers) (pp. 201-210). Ljubljana, Slovenia: Association of Economists and Managers of the Balkans, Serbia. 
4. van Herck, K., Swinnen, J., \& Vranken, L. (2013). Direct Payments and Land Rents Evidence.

5. https://www.bnb.bg/

6. https://www.mzh.government.bg/bg/

7. https://www.nsi.bg/

\section{Информация за контакт с автора:}

Редовен докторант Милен Влаев

Икономически университет - Варна

Катедра „Аграрна икономика

e-mail: milen_vlaev@yahoo.com 